\title{
Applied Managerial Decision Analysis for Debris Flow Evacuation Decisions
}

\author{
Wei-Lin LEE ${ }^{1}$, Yu-Shiu CHEN ${ }^{2}$ and Chjeng-Lun SHIEH ${ }^{3}$ \\ ${ }^{1}$ Dept. of hydraulic and ocean engineering, National Cheng Kung University (No.1, University Road, Tainan City 701, Taiwan) \\ E-mail: glaciallife@gmail.com \\ 2 Disaster prevention research center, National Cheng Kung University (No.1, University Road, Tainan City 701, Taiwan) \\ 3 Dept. of hydraulic and ocean engineering, National Cheng Kung University (No.1, University Road, Tainan City 701, Taiwan)
}

\begin{abstract}
Since 2004, debris-flow evacuation implemented based on critical rainfall intensity for warnings of debris-flow occurrences has been a regulation in Taiwan, and its many implementations in recent years have proven successful. When deciding on the rainfall intensity associated with evacuation decisions, the social cost of debris-flow disasters should be taken into account in addition to the vulnerability of the area to such disasters. However, in current practical debris-flow evacuation processes, that cost is not considered. As such, the aim of this paper is to explore how rainfall intensity and social cost relate to the decision to evacuate ahead of a debris-flow. In doing so, decision-making and cost analysis methods commonly used in management science were employed to model a rationally simplified hypothesis and develop a systematic decision-making process regarding debris-flow evacuation. This process is influenced by uncertain parameters, such as typhoon-rainfall levels and debris-flow occurrences, and determined through statistical analysis; further, the value parameters of costs in terms of deaths and evacuation payments are also considered. Finally, the model thus developed was applied to a severe debris flow disaster simulation that occurred in Taiwan in 1990 for empirical testing. Results of this study suggest that the rainfall intensity and social costs are highly pertinent to decisions regarding debris-flow evacuation when considered from a financial perspective. Moreover, by quantifying the social costs of debris-flow evacuation through decision analysis, this study may help explain the relationship between the vulnerability of an area to disasters, the social costs involved, and the decision-making criteria. It may also provide scholars a better understanding of optimal strategies for the advancement of debris-flow disaster prevention.
\end{abstract}

Key words: managerial decision analysis, debris-flow, evacuation

\section{INTRODUCTION}

Governments have the duty to help victims after disasters, the assistance of which includes the placement of victims, reconstruction and other social financial support. This assistance involves many factors and incurs heavy social costs that may delay other political objectives. Thus, evacuation is an important strategy to reduce the number of victims of debris-flow disasters during the typhoon season. By implementing evacuations, the social costs that governments will be burdened with after a disaster can be lowered.

In Taiwan, evacuations due to debris-flow can be divided into two steps. As show as Fig. 1. When the 24 hrs quantitative precipitation forecast surpasses the threshold value, the first step is activated and called "Yellow Warning". The government then attempts to persuade inhabitants to leave risk-potential area. The second step is when the real accumulated rainfall reaches the threshold value, which is called "Red Warning". In such cases, the government will force inhabitants who live in risk-potential areas to evacuate. Be that as it may, the evacuation performance of the first step is not adequate due to highly uncertain quantitative precipitation forecasts.

In practice, there are many problems from the uncertainty of rainfall. The probability of a false alarm is low during a "Red Warning" evacuation alert; however, at this time, the conditions for evacuation are not ideal. The reason is that there is insufficient time for an evacuation, and the heavy rainfall and strong winds make this work very difficult. Consequently, evacuations are usually 


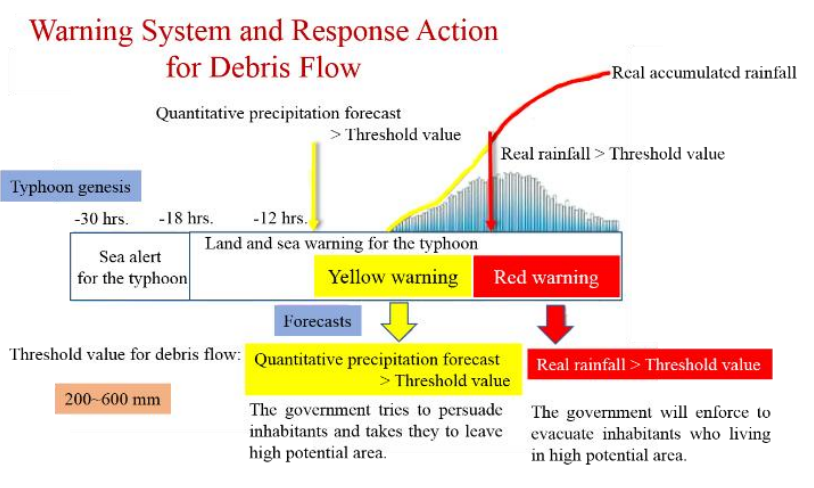

Fig. 1 Evacuation of debris-flow in Taiwan

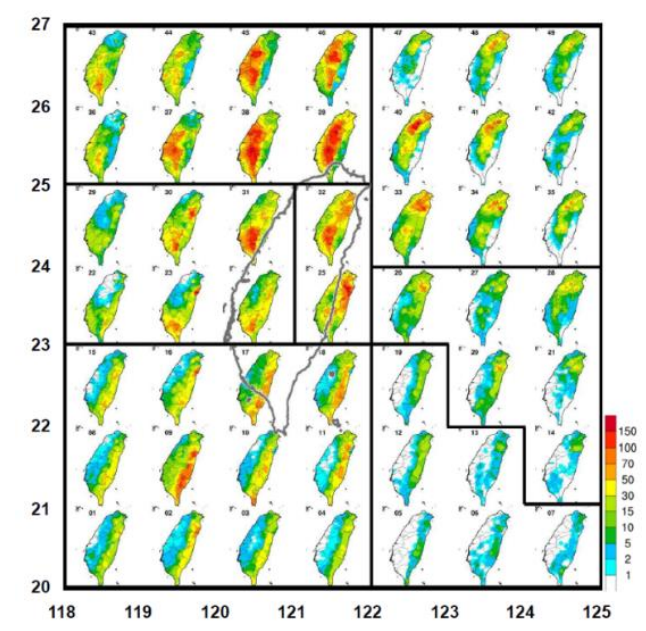

Fig. 2 The relationship between the typhoon center and spatial distribution of rainfall $(2 / 2)$

implemented when the "Yellow Warning" is issued.

However, the probability of a false alarm is normally higher during a "Yellow Warning", and inhabitants who leave their homes without a debris-flow disaster can become irate. The reason for the higher false-alarm probability is that the average distance error of typhoon tracking forecast is about 100 kilometers. As shown as Fig. 2, the size of each cell is also close to 100 kilometers and the spatial distribution of rainfall is obviously different in the individual cells. Complicating matters, inhabitants generally do not believe the government's recommendation to evacuate during a "Yellow Warning". Further, evacuations are also one type of social cost when a disaster does not occur. Moreover, it can be said that a dilemma exists when deciding to evacuate in a "Red Warning" or "Yellow Warning" due to rainfall uncertainty.

Fortunately, this dilemma could be eliminated via a cost-benefit analysis. If no cost-benefit analysis is conducted to support the decision maker, uncertainty of rainfall is the only information available to decide whether to evacuate. But if the decision maker is clearly to know cost-benefit of each option. According to the excepted value of each option, the decision maker would tend to choose the same, regardless of their risk tolerance. Therefore, the dilemma of evacuation would not confuse the decision maker when the minimum expected social cost is their consensus.

The purpose of this research was to focus on the cost-benefit analysis for debris-flow evacuation. There have been many studies and applications for typhoon tracking forecasts, quantitative precipitation forecasts, uncertainty of debris-flows, influence area of debris-flows and loss evaluations of debris-flows over the last 25 years. However, the focus of a cost-benefit analysis is commonly found in the engineering field or projects, and so is rather commonly used for decision making. Nevertheless, no standard operating procedure exists to integrate uncertainty of rainfall and debris-flow occurrences, loss from debris-flows and social costs for evacuations without disasters in cost-benefit analyses. Therefore, this study constructed a decision model for debris-flow evacuation, and estimated the excepted values for various decisions, which could be highly useful for decision makers when facing disaster situations.

\section{METHODOLOGY}

Decision analysis is a method to model a decision procedure, and the various situational decisions constitute the input parameters; then, the cost-benefit could be estimated by the model [Von Neumann and Morgenstern, 1944]. Keeney [1968] and Howard [1969] applied the expected utility theory to improve decision analysis; afterwards, the method was used frequently in management. Then, Clemen [1996] used it to research adaptive behavior of natural disasters.

The flow chart of a decision analysis includes identifying decisions, understanding objectives, identifying alternatives, understanding uncertainties and decomposing models, as shown in Fig. 3.

\subsection{Identifying decision and understanding objectives}

Lee and Liu [2004] pointed out that the purpose of evacuation is the reduction of casualties in debris-flow disasters. In this regard, Whitehead [2003] mentioned that the social costs for evacuation and the losses from a disaster should satisfy the rule of proportionality. From another perspective, the social cost for evacuation should not be higher than the losses of the disaster; 
International Journal of Erosion Control Engineering Vol. 10, No. 1, 2017

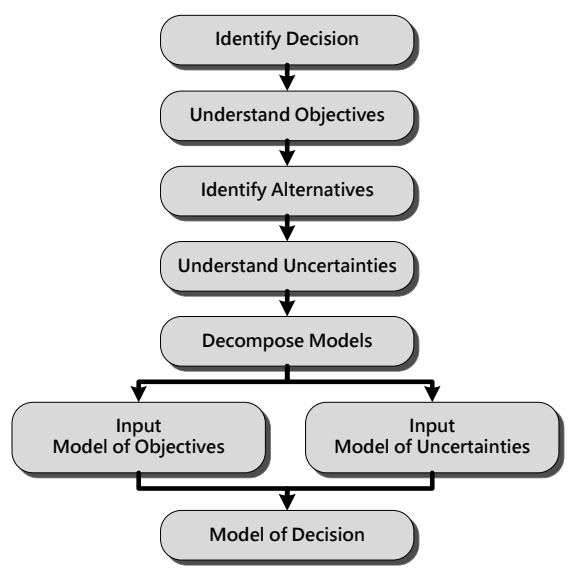

Fig. 3 Flow chart of decision analysis

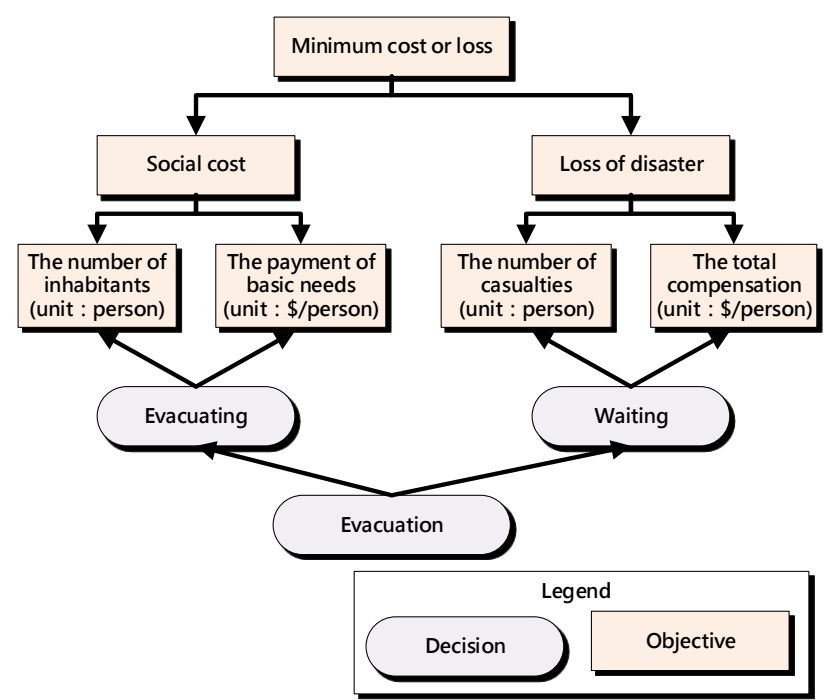

Fig. 4 Hierarchical objectives

otherwise it will defeat the purpose of evacuation reduction of disaster losses. As such, the best decision for evacuation will be made according to minimum social cost or disaster loss.

The social cost of evacuation results from the amount of inhabitants. In order to temporarily move people away from a high potential region, the government usually arranges shelters and offers them basic needs. The maintenance of shelters and payment of basic needs are the main objectives for social costs, which will increase with the number of inhabitants and the days of staying in the shelter.

The disaster loss is estimated by the area of debris-flow overflow. Because casualties are usually caused by debris-flows, the number of casualties could be estimated by the area size of the debris-flow overflow. Hence, the number of casualties and the total compensation are the main objectives for disaster loss estimation.

After decision identification and objectives understanding, the hierarchical objectives can be represented, as given in Fig. 4. Moreover, it is
Table 1 Risk matrix for the disaster response

\begin{tabular}{|c|c|c|}
\hline \multirow{2}{*}{ Alternatives } & \multicolumn{2}{|c|}{ Natural disaster } \\
\cline { 2 - 3 } & Didn't happened & Happened \\
\hline Waiting & None & Loss of disaster \\
\hline Evacuating & $\begin{array}{c}\text { Social cost of } \\
\text { evacuation }\end{array}$ & $\begin{array}{c}\text { Social cost of } \\
\text { evacuation }\end{array}$ \\
\hline
\end{tabular}

imperative to know the relationships between decisions and objectives.

\subsection{Identifying alternatives and understanding uncertainty \\ Burton et al. [1978] pointed out that there are} two alternatives for avoiding natural disasters that lead to four possible outcomes. First, the choice is waiting and the disaster occurred, which means that there is disaster loss. Second, the choice is also waiting but without a disaster, and so no disaster loss or evacuation social costs are incurred. Third, is evacuating and the disaster occurred, which means that there is no disaster loss but a social evacuation cost is incurred. Fourthly, evacuation is conducted but without the disaster, which entails the same social cost of evacuation as the third situation. These alternatives can be arranged into a risk matrix, as presented in Table 1.

The uncertainty of debris-flow disasters is composed of internal and external conditions. The internal condition presents on the occurrence of debris-flows induced by rainfall. While slope failure or bank erosion is active in the catchment, debris-flows are triggered by rainfall due to sediment carried in the river. Consequently, the occurrence of debris-flows induced by rainfall will be higher in this situation. The external condition, however, comprises the probability of accumulated rainfall. As mentioned in the introduction, spatial distribution of rainfall will be influenced by typhoon tracking. Thus, the probability of accumulated rainfall will be different according to the various types of typhoon tracking.

After identifying alternatives and uncertainty understanding, decision trees can be applied to outline the relationship between with alternatives and uncertainties, as given in Fig. 5.

\subsection{Decompose models}

After identifying decisions and alternatives and understanding objectives and uncertainties, models can be decomposed by expected utility theory, as shown in Table 2. For each external condition, two alternatives can be decomposed. Hence, the expected value of "waiting" and "evacuating" can be evaluated. The formula for expected value is expressed as 


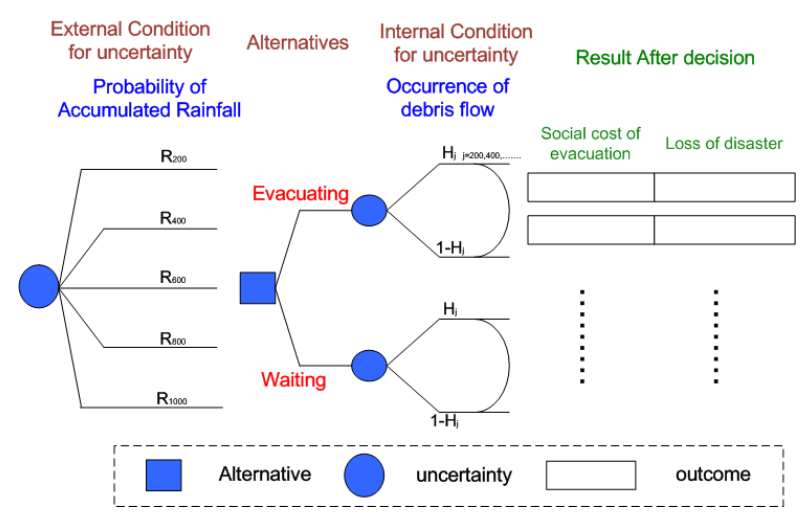

Fig. 5 Decision tree for evacuation decision

Table 2 Expected value for each decision

\begin{tabular}{|c|c|c|c|c|}
\hline $\begin{array}{c}\text { External } \\
\text { condition }\end{array}$ & Alternatives & $\begin{array}{c}\text { Internal } \\
\text { condition }\end{array}$ & $\begin{array}{c}\text { Cost or } \\
\text { Loss }\end{array}$ & $\begin{array}{l}\text { Expected } \\
\text { value }\end{array}$ \\
\hline \multirow{4}{*}{$200 \mathrm{~mm}$} & \multirow{2}{*}{ Waiting } & $\begin{array}{l}\text { Didn't happen } \\
(1-\mathrm{P}(\mathrm{X}))\end{array}$ & None & \multirow{2}{*}{$\begin{array}{l}\text { Expected } \\
\text { value }\end{array}$} \\
\hline & & $\begin{array}{l}\text { Happened } \\
\mathrm{P}(\mathrm{X})\end{array}$ & Loss & \\
\hline & \multirow{2}{*}{ Evacuating } & $\begin{array}{l}\text { Didn't happen } \\
(1-\mathrm{P}(\mathrm{X}))\end{array}$ & Cost & \multirow{2}{*}{$\begin{array}{l}\text { Expectec } \\
\text { value }\end{array}$} \\
\hline & & $\begin{array}{l}\text { Happened } \\
\mathrm{P}(\mathrm{X})\end{array}$ & Cost & \\
\hline \multirow{4}{*}{$400 \mathrm{~mm}$} & \multirow{2}{*}{ Waiting } & $\begin{array}{c}\text { Didn't happen } \\
(1-\mathrm{P}(\mathrm{X}))\end{array}$ & & \multirow[b]{2}{*}{$\cdots \cdots$} \\
\hline & & $\begin{array}{l}\text { Happened } \\
\mathrm{P}(\mathrm{X})\end{array}$ & & \\
\hline & \multirow{2}{*}{ Evacuating } & $\begin{array}{c}\text { Didn't happen } \\
(1-\mathrm{P}(\mathrm{X}))\end{array}$ & $\ldots \ldots$ & \multirow[b]{2}{*}{$\cdots \cdots$} \\
\hline & & $\begin{array}{l}\text { Happened } \\
\mathrm{P}(\mathrm{X})\end{array}$ & 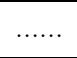 & \\
\hline
\end{tabular}

Expected value $=$ Probability $\mathrm{X}$ Cost or Loss

The external and internal conditions can be calculated by historical typhoon events and records of debris-flows. For estimation of external conditions, statistical and classed intervals of accumulated rainfall $200 \mathrm{~mm}$ each were used. Thus, the probability of accumulated rainfall can be written as in the following.

$$
H_{\mathrm{k}}=R H / h_{\mathrm{k}}
$$

$H_{\mathrm{k}}:$ Probability of accumulated rainfall

$R H:$ Times of historical typhoons

$h_{\mathrm{k}}$ : Times in the $k$ interval of accumulated rainfall

$k: 200 \mathrm{~mm}, 400 \mathrm{~mm}, 600 \mathrm{~mm}, 800 \mathrm{~mm}, 1000 \mathrm{~mm}$

For internal condition estimation, this study combined the R-I model [Shieh and Shieh, 2002] and the envelope method. The R-I model is presented by empirical formula and is expressed as

$$
R_{t}+\mathrm{a} I=C
$$

$R_{t}:$ Accumulated Rainfall (mm)

$I$ : Intensity of Rainfall ( $\mathrm{mm} / \mathrm{hr})$

$C$ : A number represent probability of debris-flow occurrence

a : Constant

Then, the envelope method [Lee and Jan, 2006] is used to calculate probability. After

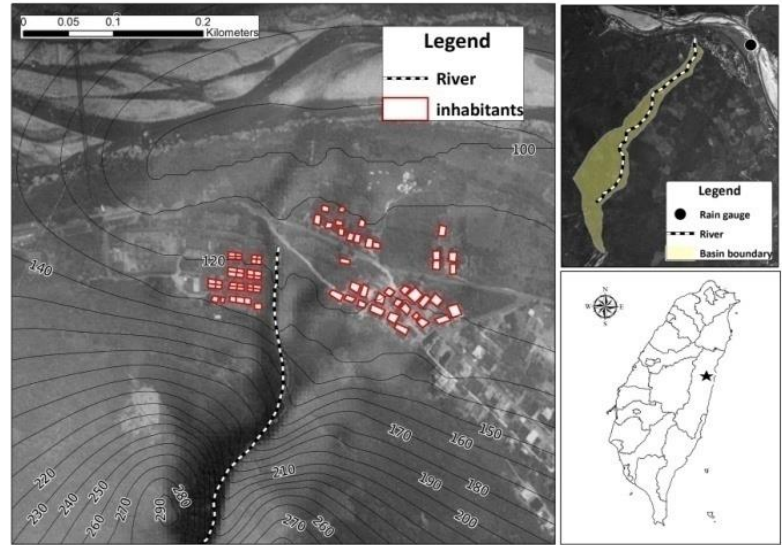

Fig. 6 Location of Tongmen Village

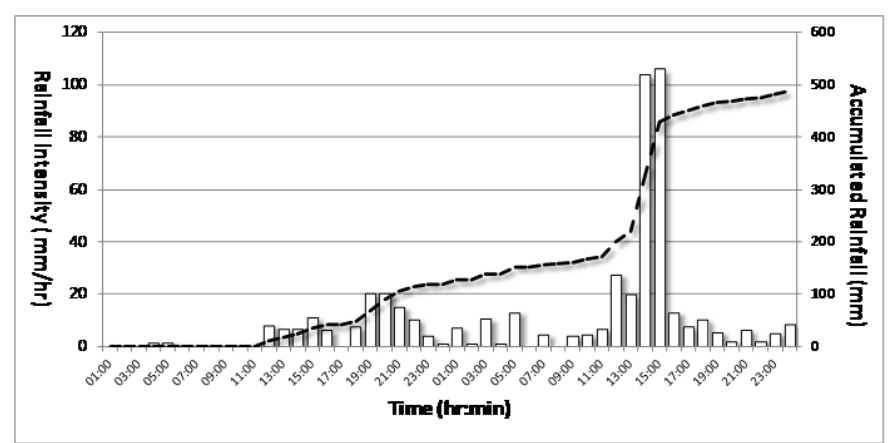

Fig. 7 Rainfall histogram of typhoon OFELIA

envelope line $C_{90}$ and $C_{10}$ are chosen, the probability for a debris-flow occurrence can be written as

$$
\frac{C-C_{10}}{C_{90}-C_{10}}=\left[\frac{\mathrm{P}(\mathrm{X})-0.1}{0.9-0.1}\right]^{2}
$$

Finally, the business software Flo-2D was applied to assess the influence area of the debris-flow overflow. The software can model two dimensions of debris-flow under various accumulated rainfall conditions by a physical mechanism. After the model simulation is complete, influence area is circled as the flow depth is higher than $50 \mathrm{~cm}$. Afterwards, the spatial distribution of the research overlap influence area is built by geographic information system. The number of inhabitants and casualties can then be calculated for decision analysis.

\section{STUDY}

\subsection{Background}

On June 23rd, 1990, typhoon OFELIA brought heavy rainfall to eastern Taiwan, resulting in the deaths of the entire population of Tongmen Village. Consequently, this work chose this location as the study area. The location of Tongmen Village is shown in Fig. 6.

The rainfall histogram according to rain-gauge records is presented in Fig. 7. The accumulated 


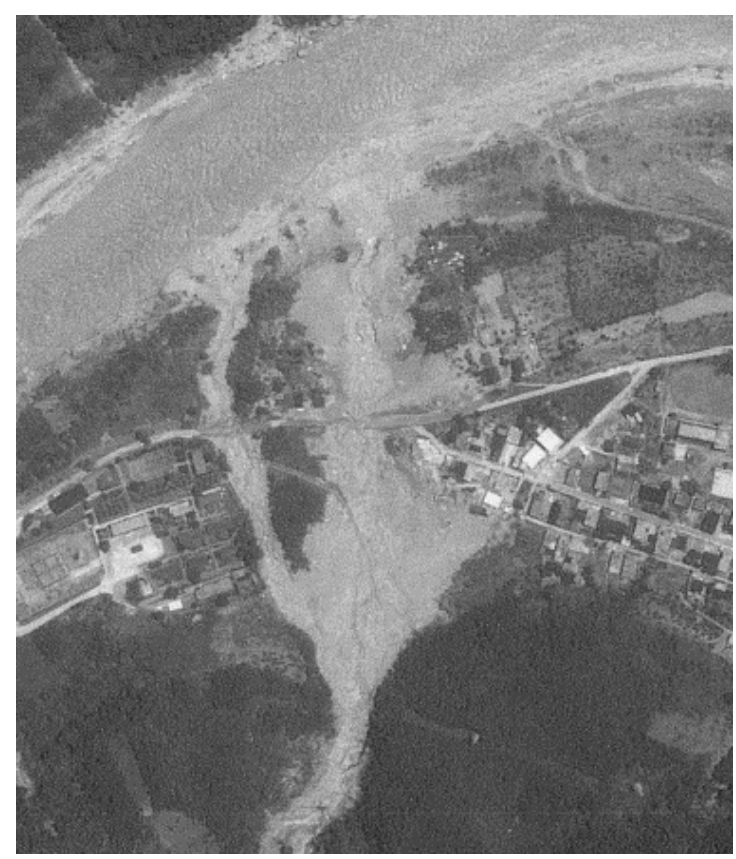

Fig. 8 Influence area of debris-flow in Tongmen Village

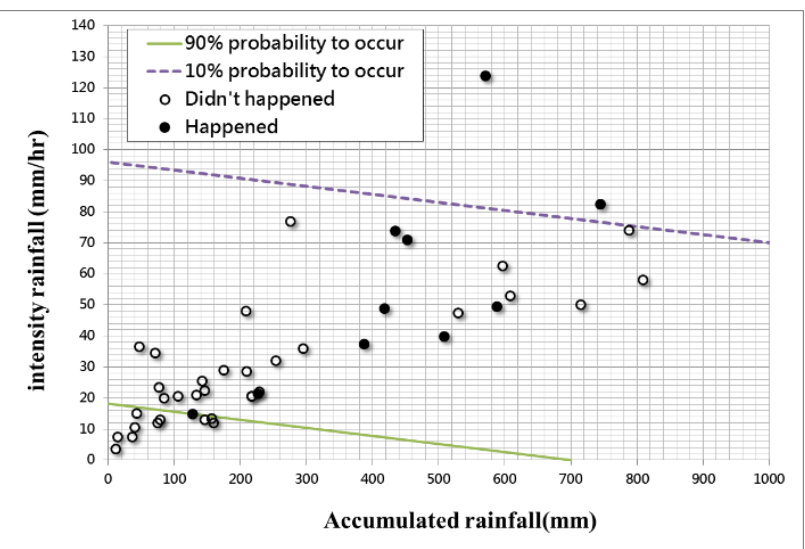

Fig. 9 Plot of the accumulated rainfall and rainfall intensity

rainfall reached $490 \mathrm{~mm}$, with the maximum intensity rainfall being $106 \mathrm{~mm} / \mathrm{hr}$. Further, the influence area of the debris-flow overflow is represented by the aerial photo shown in Fig. 8 .

\subsection{Model of uncertainties}

Firstly, the internal condition of uncertainty was estimated. According to rain-gauge records from 1961 to 2006, a plot can be drawn to show the accumulated rainfall and rainfall intensity of the historical typhoon events, as shown in Fig. 9. Further, the occurrence of debris-flows under various accumulated rainfalls can be calculated by historical typhoon events, as in Table 3.

Secondly, the external condition of uncertainty was analyzed. The Central Weather Bureau (CWB) has recorded statistical information of historical typhoon events since 1911 and obtained corresponding probabilities of typhoon tracks, as illustrated in Fig. 10. Rain-gauge records from 1961
Table 3 Occurrence of debris-flows according to accumulated rainfall

\begin{tabular}{|c|c|}
\hline Accumulated rainfall(mm) & Occurrence of debris-flow \\
\hline 200 & $0 \%$ \\
\hline 400 & $64 \%$ \\
\hline 600 & $80 \%$ \\
\hline 800 & $93 \%$ \\
\hline 1000 & $100 \%$ \\
\hline
\end{tabular}

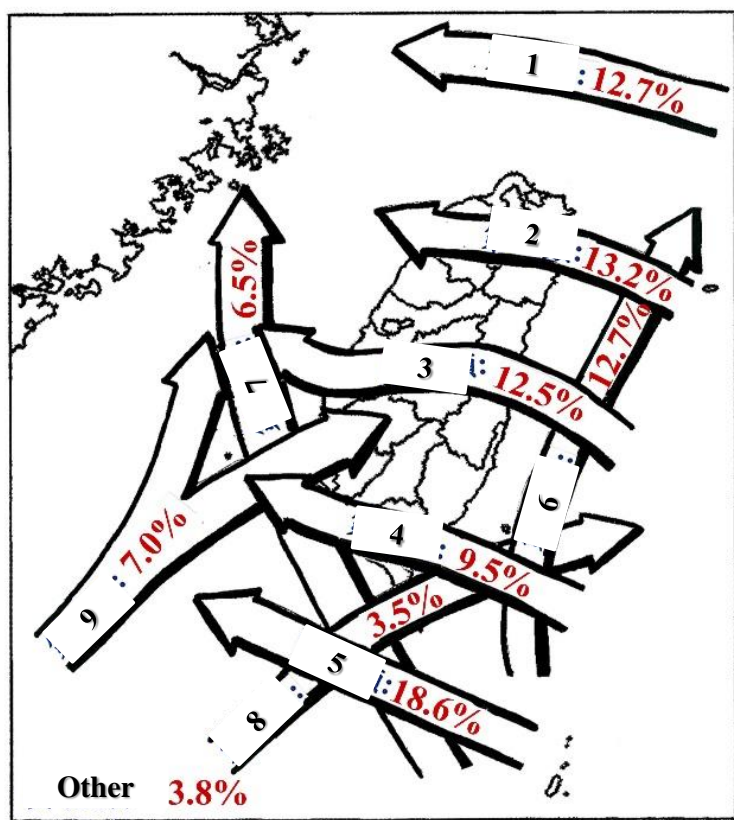

Fig. 10 Probability of typhoon trackings

to 2007 were reviewed, which allowed for the probability of accumulated rainfall from various typhoon trackings to be analyzed statistically. The results are given in Table 4.

\subsection{Model of objectives}

Chao and Lin [2004] applied a two-dimension debris-flow model, which was named "Flo-2D", to estimate the influence area of debris-flow overflow. Thus, this study used the model to simulate the influence area of debris-flow overflow under various accumulated rainfall conditions. The parameters of Flo-2D are used in the model and presented in Table 5, with outcomes from the model shown in Fig. 11.

Then, the Geographic Information System (GIS) was applied to overlap the influence area with the village location. According to the spatial relationship between the influence area and buildings from the aerial photo, the number of inhabitants and the number of evacuees can be estimated, as shown in Table 6.

In Table 6, the value for compensation is according to Xue and Wang [1988] in the "Estimation of the value of life for employed workers in Taiwan." They estimated the value of life 
Table 4 Probability of accumulated rainfall from various typhoon tracking

\begin{tabular}{|c|c|c|c|c|c|}
\hline \multicolumn{7}{|c|}{ Accumulated Rainfall } \\
\hline $\begin{array}{c}\text { Typhoon } \\
\text { tracking }\end{array}$ & $200 \mathrm{~mm}$ & $400 \mathrm{~mm}$ & $600 \mathrm{~mm}$ & $800 \mathrm{~mm}$ & $1000 \mathrm{~mm}$ \\
\hline 1 & $100 \%$ & $0 \%$ & $0 \%$ & $0 \%$ & $0 \%$ \\
\hline 2 & $84 \%$ & $16 \%$ & $0 \%$ & $0 \%$ & $0 \%$ \\
\hline 3 & $38 \%$ & $33 \%$ & $10 \%$ & $14 \%$ & $5 \%$ \\
\hline 4 & $46 \%$ & $31 \%$ & $15 \%$ & $0 \%$ & $8 \%$ \\
\hline 5 & $38 \%$ & $38 \%$ & $14 \%$ & $3 \%$ & $7 \%$ \\
\hline 6 & $73 \%$ & $7 \%$ & $10 \%$ & $10 \%$ & $0 \%$ \\
\hline 7 & $57 \%$ & $14 \%$ & $14 \%$ & $14 \%$ & $0 \%$ \\
\hline 8 & $100 \%$ & $0 \%$ & $0 \%$ & $0 \%$ & $0 \%$ \\
\hline 9 & $73 \%$ & $0 \%$ & $27 \%$ & $0 \%$ & $0 \%$ \\
\hline ALL & $63 \%$ & $19 \%$ & $10 \%$ & $5 \%$ & $3 \%$ \\
\hline
\end{tabular}

Table 5 Parameters of Flo-2D

\begin{tabular}{|c|c|}
\hline \multicolumn{2}{|c|}{ Flo-2D } \\
\hline \multicolumn{2}{|c|}{ Bingham Yield Stress $\left(\tau_{\mathrm{y}}=\alpha \mathrm{e}^{\beta}\right)$} \\
\hline$\tau_{\mathrm{y}}($ dynes $/ \mathrm{cm} 2)$ & 25000 \\
\hline$\alpha$ & 0.01 \\
\hline$\beta$ & 21.988 \\
\hline Bingham Viscous number $\left(\eta=\alpha \mathrm{e}^{\beta}\right)$ \\
\hline$\eta($ dynes-s/cm2) & 150 \\
\hline$\alpha$ & 0.01 \\
\hline$\beta$ & 14.352 \\
\hline manning coefficient $\mathrm{n}$ & 0.15 \\
\hline density of sedment $\mathrm{G}_{\mathrm{s}}$ & 2.65 \\
\hline fiction number $\mathrm{K}$ & 2285 \\
\hline olume Concentration $\mathrm{C}$ & 0.67 \\
\hline $\begin{array}{c}\text { Accumulated Rainfall } \\
(\text { mm })\end{array}$ & Discharge $\left(\mathrm{m}^{3} / \mathrm{s}\right)$ \\
\hline $0-200$ & 2.7 \\
\hline $200-400$ & 6.5 \\
\hline $400-600$ & 10.4 \\
\hline $600-800$ & 14.3 \\
\hline $800-1000$ & 18.2 \\
\hline
\end{tabular}

according to how much money could be earned over their full lives, which showed that the average value of life in Taiwan is around 34 million NTD. Therefore, this value was used as the maximum compensation.

In Table 6, the payment for evacuation is in accordance with the regulations in Taiwan. Because debris-flows are very severe natural disasters, the central government announced a regulation for local governments to perform evacuations. According to regulations, the maximum payment for evacuation is

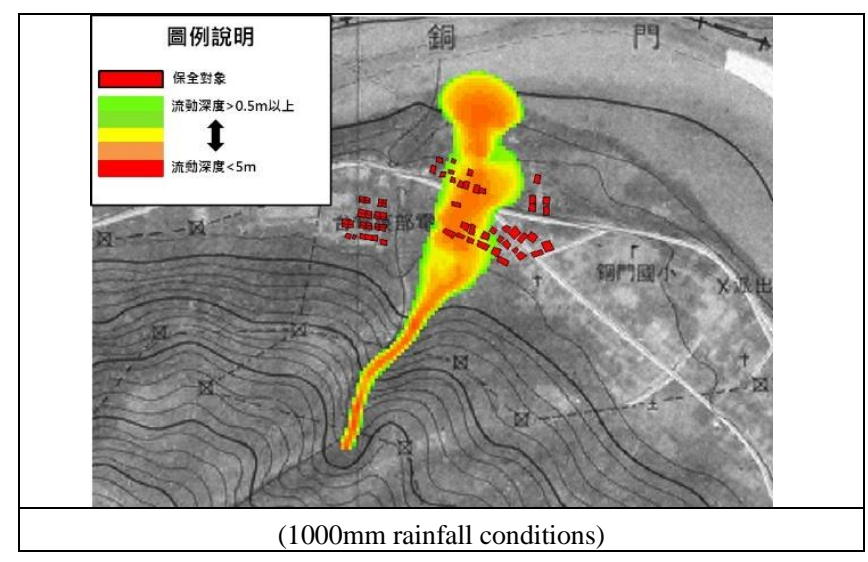

Fig. 11 Outcomes from the model under various accumulated rainfall conditions

Table 6 Parameters from influence area

\begin{tabular}{|c|c|c|c|c|}
\hline $\begin{array}{c}\text { Accumulated } \\
\text { Rainfall } \\
(\mathrm{mm})\end{array}$ & $\begin{array}{c}\text { inhabitants } \\
\text { (persons) }\end{array}$ & $\begin{array}{c}\text { compensation } \\
\text { (ten thousand } \\
\text { NTD/ } \\
\text { person) }\end{array}$ & $\begin{array}{c}\text { Number } \\
\text { of } \\
\text { evacuees } \\
\text { (persons) }\end{array}$ & $\begin{array}{c}\text { Payment } \\
\text { for } \\
\text { evacuation } \\
\text { (ten } \\
\text { thousand } \\
\text { NTD/ } \\
\text { person) }\end{array}$ \\
\hline $0 \sim 200$ & 5 & $20 \sim 3400$ & 213 & $2 \sim 20$ \\
\hline $200 \sim 400$ & 10 & $20 \sim 3400$ & 213 & $2 \sim 20$ \\
\hline $400 \sim 600$ & 11 & $20 \sim 3400$ & 213 & $2 \sim 20$ \\
\hline $600 \sim 800$ & 12 & $20 \sim 3400$ & 213 & $2 \sim 20$ \\
\hline $800 \sim 1000$ & 13 & $20 \sim 3400$ & 213 & $2 \sim 20$ \\
\hline
\end{tabular}

200 thousand NTD; thus, this value was set as the maximum evacuation payment.

\subsection{Decision model}

After the model of uncertainties and objectives was built, these results were used in the decision model. In the decision model, the expected decision value was calculated for various accumulated rainfalls. In Table 7, the value of compensation is 12 million NTD while the evacuation payment is 20 thousand NTD. Then, the loss or cost for each alternative can be calculated depending on the objectives model. Finally, the expected value can be obtained by the loss or cost double with occurrence of debris-flow.

As shown in Table 7, there are two alternatives in an accumulated rainfall; hence, there is an expected value for each alternative. According to the purpose of evacuation that is the maximum disaster loss or social cost, the alternatives that are the best decision for various accumulated rainfalls can be identified. In the case of Table 7, the best decision is that evacuation is implemented when the accumulated rainfall is over $200 \mathrm{~mm}$.

\section{DISCUSSION}

In this case study, the occurrence of debris-flow 
Table 7 Expected value for evacuation decision

\begin{tabular}{|c|c|c|c|c|}
\hline $\begin{array}{c}\text { Accumula } \\
\text { ted } \\
\text { Rainfall }\end{array}$ & $\begin{array}{c}\text { Alternat } \\
\text { ives }\end{array}$ & $\begin{array}{c}\text { Occurrence of } \\
\text { debris-flow }\end{array}$ & $\begin{array}{c}\text { Loss or Cost } \\
\text { (ten } \\
\text { thousand) }\end{array}$ & $\begin{array}{l}\text { Expected } \\
\text { value (ten } \\
\text { thousand) }\end{array}$ \\
\hline \multirow{4}{*}{$200 \mathrm{~mm}$} & \multirow{2}{*}{ Evacuating } & Not happened $100 \%$ & 426 & \multirow{2}{*}{426} \\
\hline & & Happened $0 \%$ & 426 & \\
\hline & \multirow{2}{*}{ Waiting } & Not happened $100 \%$ & 0 & \multirow{2}{*}{0} \\
\hline & & Happened $0 \%$ & 6000 & \\
\hline \multirow{4}{*}{$400 \mathrm{~mm}$} & \multirow{2}{*}{ Evacuating } & Not happened $36 \%$ & 426 & \multirow{2}{*}{426} \\
\hline & & Happened $64 \%$ & 426 & \\
\hline & \multirow{2}{*}{ Waiting } & Not happened $36 \%$ & 0 & \multirow{2}{*}{7680} \\
\hline & & Happened $64 \%$ & 12000 & \\
\hline \multirow{4}{*}{$600 \mathrm{~mm}$} & \multirow{2}{*}{ Evacuating } & Not happened $20 \%$ & 426 & \multirow{2}{*}{426} \\
\hline & & Happened $80 \%$ & 426 & \\
\hline & \multirow[b]{2}{*}{ Waiting } & Not happened $20 \%$ & 0 & \multirow{2}{*}{10560} \\
\hline & & Happened $80 \%$ & 13200 & \\
\hline \multirow{4}{*}{$800 \mathrm{~mm}$} & \multirow{2}{*}{ Evacuating } & Not happened $7 \%$ & 426 & \multirow{2}{*}{426} \\
\hline & & Happened 93\% & 426 & \\
\hline & \multirow{2}{*}{ Waiting } & Not happened $7 \%$ & 0 & \multirow{2}{*}{13392} \\
\hline & & Happened $93 \%$ & 14400 & \\
\hline \multirow{4}{*}{$1000 \mathrm{~mm}$} & \multirow{2}{*}{ Evacuating } & Not happened $0 \%$ & 426 & \multirow{2}{*}{426} \\
\hline & & Happened $100 \%$ & 426 & \\
\hline & \multirow{2}{*}{ Waiting } & Not happened $0 \%$ & 0 & \multirow{2}{*}{15600} \\
\hline & & Happened $100 \%$ & 15600 & \\
\hline
\end{tabular}

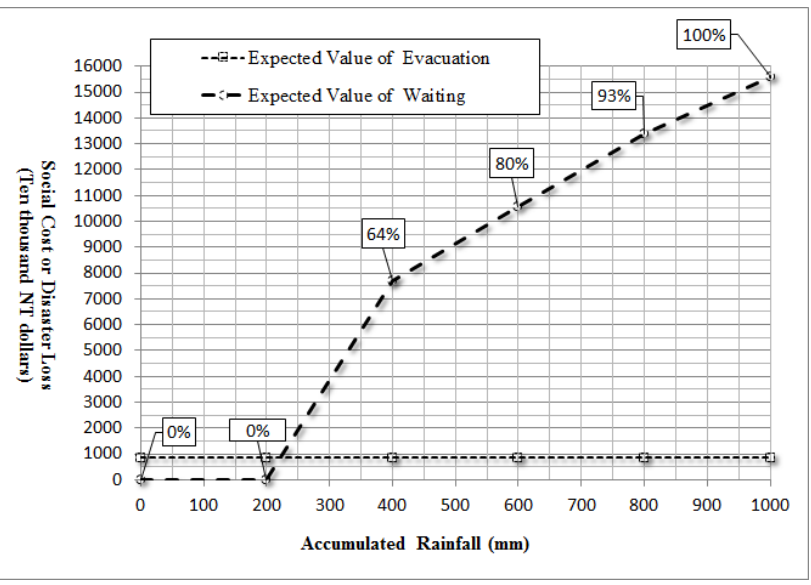

Fig. 12 Expected decision value under the "Red Warning"

was very high when the accumulated rainfall was over $400 \mathrm{~mm}$. Depending on the results from the decision model, the optimum decision is also evacuation before the accumulated rainfall reaches $400 \mathrm{~mm}$. The best decision is based on the purpose of evacuation that comprises the minimum social cost and disaster loss. Accordingly, Fig. 12 presents a plot based on Table 7. As shown, the expected value of evacuating is higher than the expected value of waiting when the accumulated rainfall is over $400 \mathrm{~mm}$. Therefore, the best decision for evacuation can be made via the decision analysis.

Then, the evacuation scenario was changed from "Red warning" to Yellow Warning. At this moment, evacuation uncertainty should not only

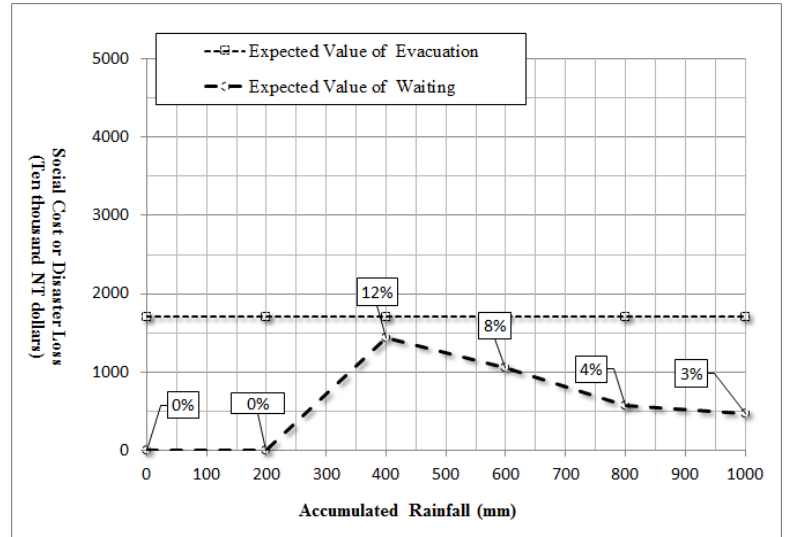

Fig. 13 Expected decision value $72 \mathrm{hrs}$ before a typhoon approaches Taiwan

consider internal conditions, but should also involve external conditions. As mentioned in the introduction, the typhoon location is highly related with the spatial distribution of rainfall. Hence, the occurrence of debris-flows should double with the accumulated rainfall probability in various typhoon trackings. In this scenario, the probability of accumulated rainfall is denoted as "ALL" in Table 4. Moreover, this "Yellow Warning" is usually 3 days before a typhoon approaches Taiwan, which means that the payment for evacuation is triple due to extended days in shelters. Thus, the payment for evacuation is 800 thousand under this scenario. According to these parameters, the decision model result can be represented as in Fig. 13, which also shows that waiting is the better decision at this early time. This matches reality because evacuations should not be implemented under a high uncertainty of rainfall.

Moreover, this study shortens the early time to 1 day before a typhoon approaches Taiwan. At this time, the type of typhoon tracking is usually clear and obvious. Hence, the accumulated rainfall for various typhoon trackings will differ according to type. The probability of accumulated rainfall for various typhoon trackings was given in Table. 4. Then, the payment for evacuation was changed to 400 thousand in this scenario. Therefore, the results from the decision model can be calculated, an example of typhoon tracking type 7 as in Fig. 14. The best decision is waiting for typhoon tracking types 1 and 8 . Further, the best decision is evacuation when the quantitative precipitation forecast surpasses an accumulated rainfall of 400 $\mathrm{mm}$ for typhoon tracking types $2,3,4,5$, and 7 . Lastly, the best decision is evacuation when the quantitative precipitation forecast exceeds an accumulated rainfall of $600 \mathrm{~mm}$ for typhoon tracking types 6 and 9 .

After analyzing evacuations for various timings, 


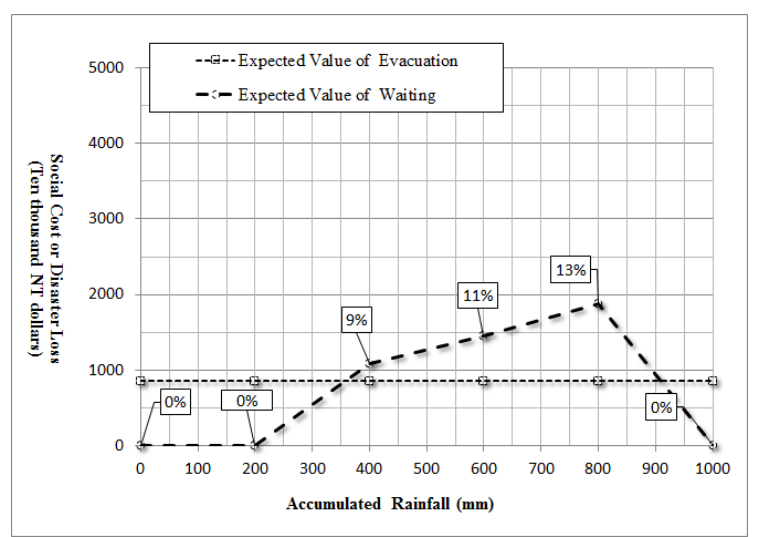

Fig. 14 Expected decision value when typhoon tracking is type 7

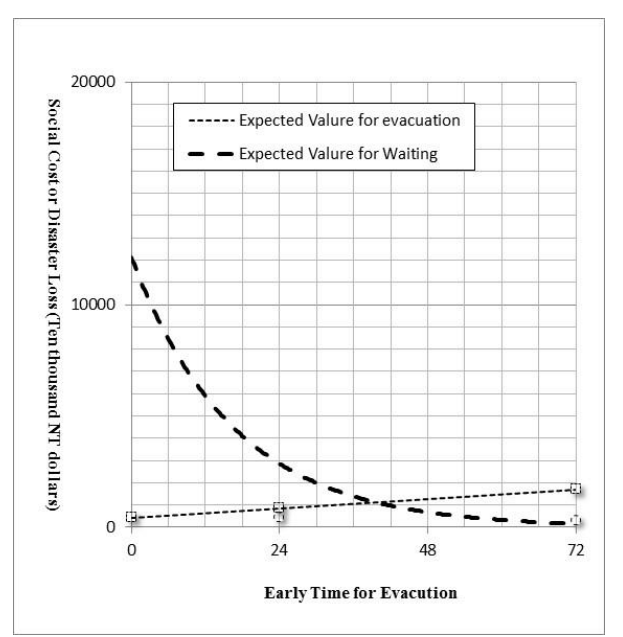

Fig. 15 Expected decision value at various early times

a tendency was found that waiting is the best decision before a typhoon approaches Taiwan while evacuation is the best decision after typhoon is near Taiwan. This means that decision analysis can be an effective method for evacuation decisions. Moreover, the expected decision value can explain changes in decision-making depending on time. As shown in Fig. 15, the expected decision value is plotted for various early times according to different scenarios. It can be found that evacuation's expected value curve and the waiting's expected value curve cross at the early time of $36 \mathrm{hrs}$. This result indicates that this moment could be the best time to conduct an evacuation.

\section{CONCLUSION}

It is critical to conduct an evacuation prior to debris-flow disasters. If an evacuation occurs during the "Red warning", the inhabitants will likely not have enough time. However, if the evacuation takes place during the "Yellow warning", the costs of the evacuation will be the social costs in accordance with the evacuation. Therefore, the decision constitutes a dilemma when the decision maker does not have enough information about the uncertainty and the costs or losses.

In this study, decision analysis was an objective method to characterize evacuation behavior. The expected value of alternatives can be estimated from various scenarios, the information of which can help a decision maker explain why they need to evacuate inhabitants. Moreover, when the best time is for evacuation is a difficult problem in practice, but the use of decision analysis can help formulate a solution. Ultimately, this study may provide scholars with a better understanding of optimal strategies for the advancement of debris-flow disaster prevention.

\section{REFERENCES}

Burton, I., Kates, R.W. and White, G.F. (1978): The environmental as hazard, Oxford University Press, New York.

Chao, C.-H. and Lin, M.-L. (2004): Numerical simulation of debris flow and the characteristic of rheological parameters, Masters dissertation, National Taiwan University, 2004.

Clemen, R.T. (1996): Making hard decision with decision tools, Duxbury Press.

Howard, R. (1969): Preference for multi-attributed alternatives, memorandum, RM-5868-DOT/RC.

Keeney, R. (1968): Evaluating multidimensional situations using a quasi-separable utility function, IEEE Transactions on Man-Machine Systems, Vol. 9, Issue 2, pp. 25-28.

Lee, H.-C. and Liu, K.-F. (2004): The cost-benefit assessment of mitigation methods for debris flow hazards, Bulletin of the College of Engineering, National Taiwan University, No. 92, pp. 105-118.

Lee, M.H. and Jan, C.-D. (2006): A rainfall-based debris-flow warning analysis and its application, Doctoral dissertation, National Cheng kung University, 2006.

Shieh, M.-L. and Shieh, C.-L. (2002): A study on cluster analysis of potential debris flow streams \& critical precipitation line in the central disaster-hit area, Masters dissertation, National Cheng kung University, 2004.

von Neumann, J. and Morgenstern, O. (1944): Theory of games and economic behavior, Princeton University Press.

Whitehead, J.C. (2003): One million dollars per mile? The opportunity costs of hurricane evacuation, Ocean \& Coastal Manage-ment, Vol. 46, Issues 11-12, pp. 1069-1083.

Xue, L.M. and Wang, S.W. (1988): Estimation of the value of life for employed workers in Taiwan, Ching chi chuan lun, No. 108 , pp. 44-45.

Received: 30 July, 2015

Accepted: 25 February, 2016 